\title{
An Analysis of Sketch Inhibition within Contemporary Design Education
}

\author{
Lisa Thurlow ${ }^{1, *}$, Peter Ford ${ }^{2}$ \\ ${ }^{1}$ School of Design, De Montfort University, Leicester, United Kingdom \\ ${ }^{2}$ Commercial Design Unit, De Montfort University, United Kingdom
}

Copyright $\bigcirc 2018$ by authors, all rights reserved. Authors agree that this article remains permanently open access under the terms of the Creative Commons Attribution License 4.0 International License

\begin{abstract}
Sketch inhibition is regularly alluded to by educators as a phenomenon within design higher education, and one having increasingly marked effects on industry - but has garnered little attention from academics. This paper provides a meta-analysis of the literature and evaluation of the anatomy and functions of sketching during design ideation across a variety of disciplines. It demonstrates the importance of sketching for cognitive support, as a language, a means of reflection, and storage of information. It presents initial findings from the literature related to symptoms; from avoidance to an over reliance on digital tools and considers its causes, ranging from psycho-social, to technological. Fine art exercises have proven beneficial to its management, however further investigation is recommended to establish depth and enable a framework for its management within HE.
\end{abstract}

Keywords Design Education, Design Methodology, Design Method(S), Design Tools, Sketch Inhibition

\section{Introduction}

This paper is based on research conducted during a year-long investigation into the little-considered phenomenon of sketch inhibition among UK design students and new graduates: an issue continually mooted among educators and industry alike, but is one that has attracted little interest from academic quarters. The findings presented here form the initial stages of a $\mathrm{PhD}$ study and offer discussion of the literature.

Sketch inhibition is an issue prevalent among higher education design courses in the UK and evidence from the literature supports this, [1-3. It is most apparent during studio-based teaching sessions and appears to be increasing as a phenomenon, its symptoms being embodied in student behaviour and the quality of design output. Industry is subsequently encountering difficulty employing new graduates with the manual ideation skills to fulfil their needs, coupled with an increase in the demand for recruits with manual sketching skills, [4]. There is a growing gap in the skillsets of design graduates, and one that education appears to be neglecting. Based upon these initial findings, an investigation into the nature and extent of sketch inhibition among student designers appears to be necessary.

\section{Aim \& Objectives}

The aim was to establish the nature and extent of sketch inhibition within design higher education, (HE), in order to develop a tool for its management. A comprehensive understanding of the characteristics and purpose of sketching relevant to the design ideation process was identified as a vital driver for the research.

Sketching as a cognitive tool serves many disciplines outside the disciplines of design, most commonly that of fine and applied art, and individual users relate to it in very specific and personal ways. However, for the purposes of this investigation a cross disciplinary approach within design was the focus. "The practice of designing has common features, regardless of the domain in which it is exercised...No matter what domain, designing involves certain characteristic activities that must be learned," [5] (p.3). Thus, a set of objectives was defined as follows: to,

1. Explore and evaluate the specific nature, scope, functions and benefits of sketching activity: its purpose within the design process,

2. Explore the internal dialogue and processes of the designer during the design ideation process: its micro-processes,

3. Establish the nature of sketch inhibition as a phenomenon and whether this is problematic to the design process,

4. Explore the nature, common causal factors and effects of sketch inhibition among designers,

5. Conduct analysis and meta-analysis of the literature using Nvivo, relevant to the aim.

During the course of the research, the literature also 
provided an invaluable foundation to the investigation in terms of identification of the issues requiring research using primary methods, and, development of appropriate research methodologies for investigation of those identified issues.

\section{Methodology}

The literature review: A broad range of keywords was developed and the literature accessed using both keyword and citation searches. Databases used included Scopus, Ebsco, Design \& Applied Arts Index, COPAC, Google Scholar, the British Library EThos database and the De Montfort University library catalogue. Forward and backward citation searches were most effective: the position of sketch inhibition within a much wider literature environment meant that the work of relatively few academics provided most impact.

Initial broad-based searches using keywords proved problematic, especially as the term 'Drawing' was functioning as a verb and returning inappropriate results, and 'Sketch' was used as a generic term for presentation of information in disciplines other than design. Initially, literature relating specifically to sketching for design concept development appeared to be virtually non-existent. Coupled with a lack of literature specific to sketch inhibition, this required an inductive approach to the research utilising literature from related areas of study. Expanding on the concept of sketch inhibition, using mind-mapping techniques where necessary provided a framework of relevant subject areas to access via the literature.

Due to sketch inhibition being so little explored within the design ideation process a grounded theory approach was taken [6] involving the use of an emergent coding strategy. Nvivo was used, initially for management of the literature, but additionally, for meta-analysis. As little had been demonstrated academically via the literature to evidence sketch inhibition, the opportunity to apply this methodology to the analysis of the literature was of interest.

Generation of keywords to retrieve data created a position from where to begin coding the literature. The literature itself became the driver for the identification of new issues, and this developed into an iterative process, creating further new nodes into which to code as the body of data grew. Although a broad approach to the type of literature was applied, and grey literature considered a possibly valuable source, the data gathered has been almost entirely peer reviewed academic journals and conference papers together with publications by practitioners and academics including those from relevant related disciplines such as psychology and semiotic theory.

\section{Key Findings from the Literature}

The literature demonstrates that sketch inhibition as a phenomenon has been touched upon by just a few papers to date. These have all focussed on the issues of inhibition among student designers and have provided validity to a study where the presence of little explicit literature has been an issue.

Meta-analysis of the literature

Over thirty individual nodes have been identified relating to the issues of sketch inhibition, and a further code specifically for the methodologies of experiments demonstrated within the literature.

Three levels of information have been emergent during analysis, that of:

1. The nature of sketching for design, (its purposes and micro-processes),

2. Issues of the individual, and,

3. Group and societal issues.

The following models illustrate the number of literature sources that provided data for nodes, (figure 1), and number of individual codings within Nvivo for each of those nodes, (figure 2). These demonstrate the lack of literature related directly to sketch inhibition, expertise and design fixation, but present a large body related to education and the processes within sketching. 


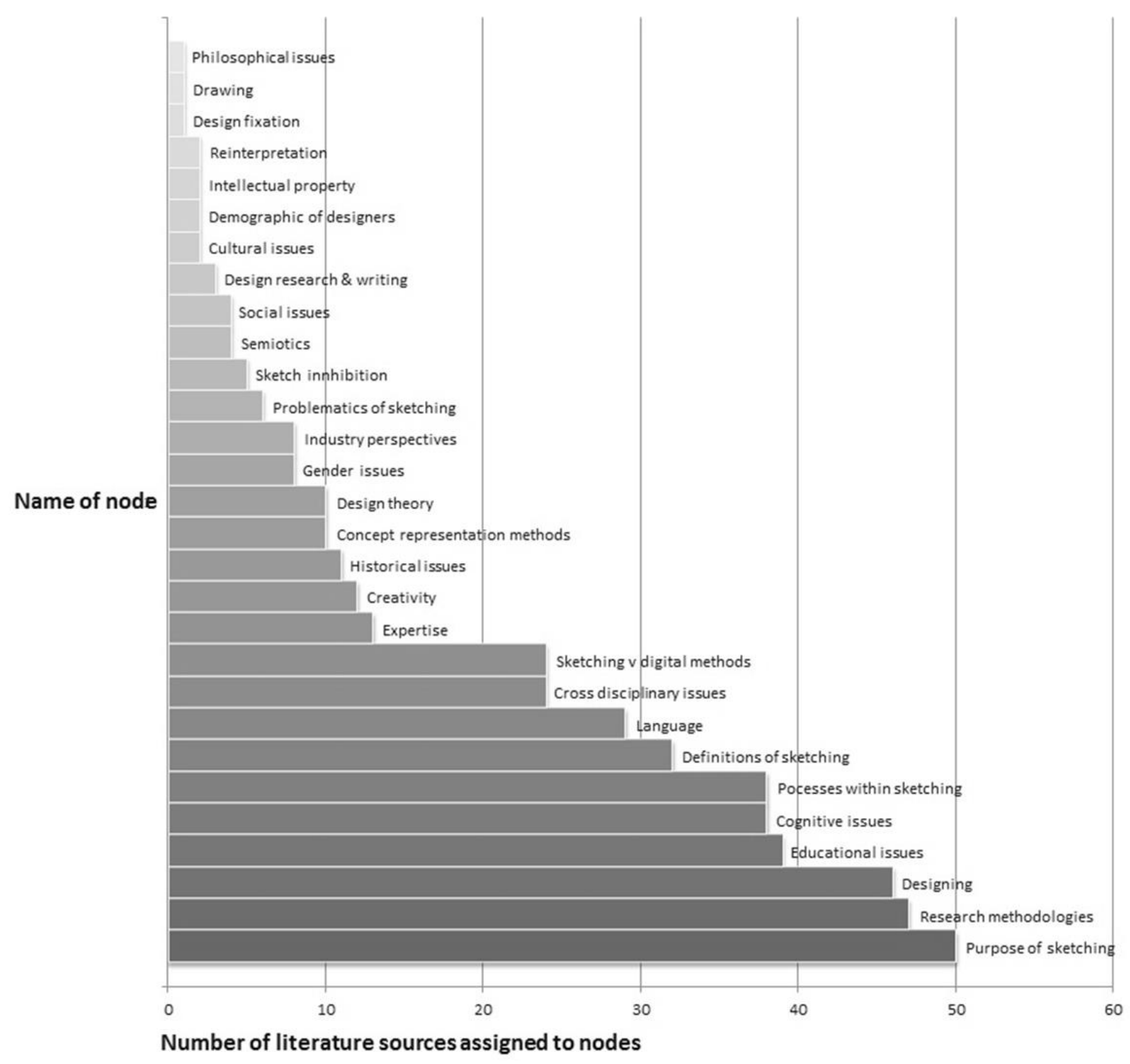

Figure 1. Model to show the number of literature sources assigned to individual nodes in NVivo

The lack of correlation between the empirical evidence regarding sketch inhibition among undergraduate designers and the volume of the literature relating directly to it is perplexing. Their specific contribution to the research by Leblanc [1] Booth et al. [3] and Hu et al. [2], has been unquestionable, but begs the question as to why so little explicit literature about sketch inhibition has ever been published, and why the issue has only come to light through said literature in the last three years.

The areas from where the literature has been produced raises further questions. There are disciplines for which writing is the norm, and others for which no literature has been available: craft-based disciplines such as ceramics have not featured in the literature at all. Engineering and architecture have been the most widely documented disciplines to utilise sketching in their processes and the most prolific disciplines from where literature has been accessed, see figure 3. This is unsurprising as these disciplines are embedded more deeply within academia than the craft-based disciplines of textiles and ceramics.

Gross \& Do [5] also suggest that other disciplines take from the tradition of academic writing from architecture, “... one of the few subjects where design is the primary focus of university education; therefore architectural education offers valuable lessons for teaching design in other domains," (p.1). The process of architectural design involves meta-analysis and representation though scale models and drawings, whereas craft-based disciplines involve a more direct and immediate relationship with their respective materials. Architecture and engineering also require the production of conscription devices and bodies of written information in order to be realised: the tradition of academic rigour of such disciplines could offer an explanation as to their strong influence over the literature for this study. 


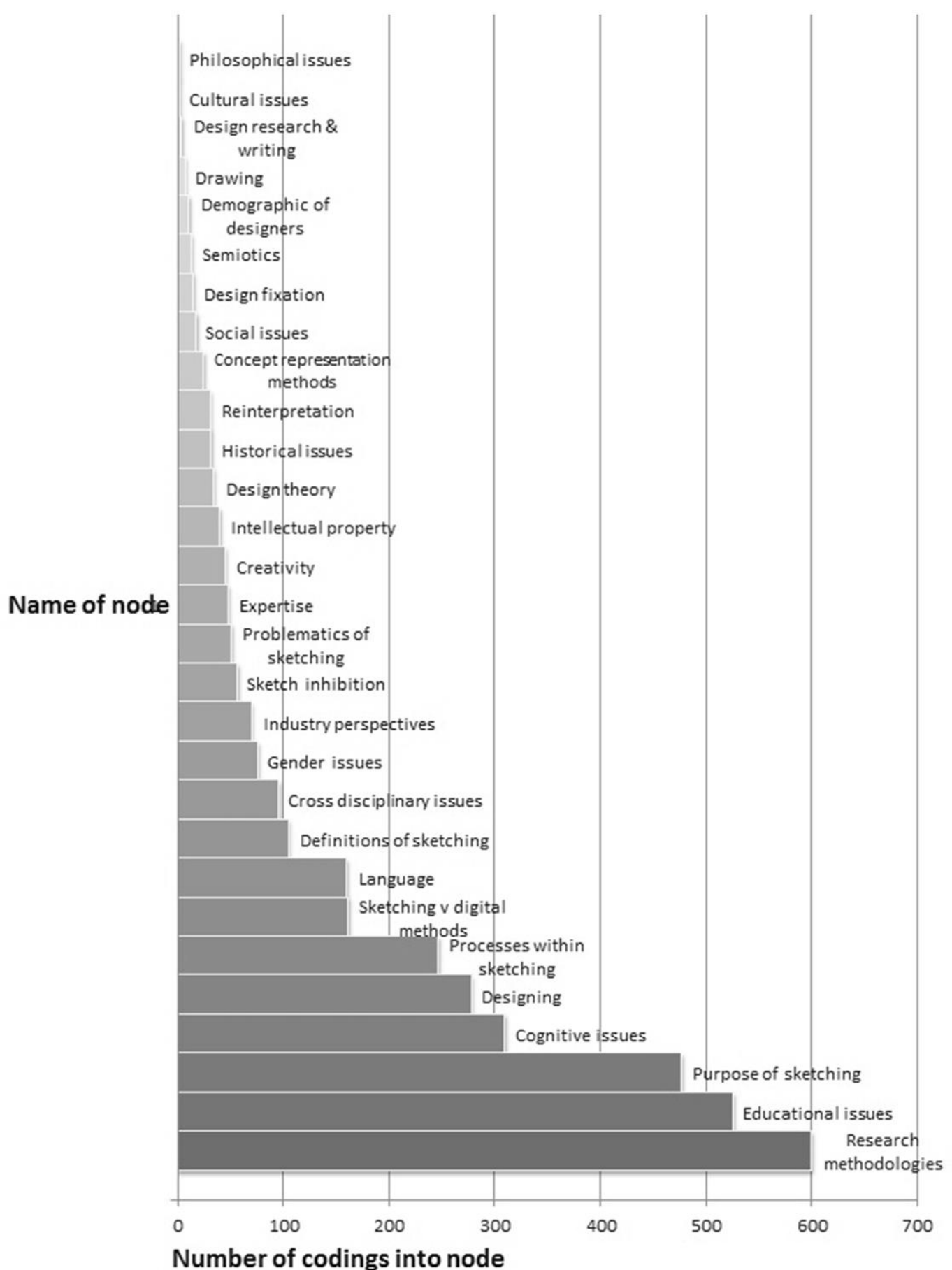

Figure 2. Model to show the number of codings within each node in NVivo 


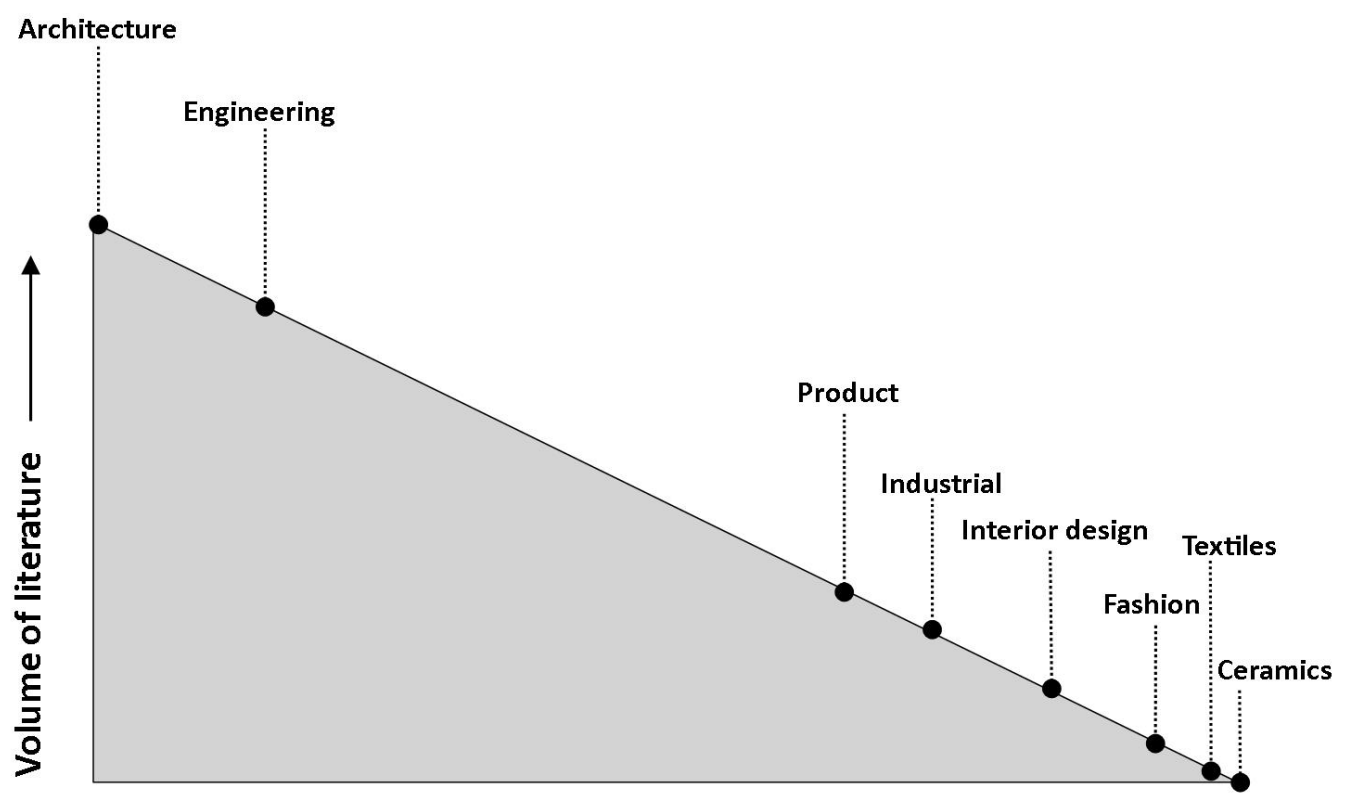

Figure 3. Model to show the body of literature accessed in relation to sketching during the course of the study.

\section{The Purpose of Sketching during Design Ideation}

The literature is presented here by way of a narrative of sketching, its purpose, functions and position in education in order to frame a holistic understanding of its importance.

Bilda et al. [7] conducted protocol analysis experiments to establish the relevance of sketching during design development. They established from participant interviews that sketching imparts a dialogue: "you can't stop the messages coming back from each line you put down," They observe the relationship between elements within the sketch, "...seeing it in parts and seeing it as a whole...the whole emerges from and cannot exist without the parts but depends on the relationship between the parts". They consider re-representation: "Half the process is drawing it, and drawing it.... and eventually...something sort of creeps out at you," (p.12) which is further considered by Goel, [8]. They consider the importance of externalisation of mental imagery, "the vision is in your mind and then you are putting it down...it is the image (that) moves the pencil," Sketching as a form of language is also considered, (as is the case with much of the literature relating to the purpose of sketching): "... as you think you speak...If you think first and then speak, it would all come out differently...It is like a language you learn to talk and it's essential that you do," (p.12). Bilda \& Gero [9] also identify issues of working memory limitation among non-sketchers and the importance of sketching as a means to offload this.

Goldschmidt [10], suggests the benefits of sketching include, by default, access to the history of the creative process as serial information whereby complete sets of developmental information can be kept. On the economy of sketching, she proffers that no cognitive energy is used in converting marks into readable information - marks on the page just are.

Kosslyn's [11] research into mental imagery has informed understanding of the cognitive importance of sketching to the design development process and has been referred to widely by others during the course of this review. His research suggests there are two types of mental representation: propositional and depictive. The propositional representation constitutes a mental sentence whereby the subject creates their own imagery, such as a verbal description or instruction. It is linear, has a predicate, (action), and is composed of entities, e.g., a ball sitting on a box. The depictive representation, of which the sketch is an example, is by contrast an entity with a configuration in a spatial context. Kosslyn's work also confirms a literal, physiological connection between image and brain: experiments demonstrate that a majority of neurons within the visual cortex are positioned to mirror those of the retina, spatial imagery effectively replicating real world environments. To illustrate this he used an experiment to mentally visualise a boat with an anchor and porthole to demonstrate that the further away a component is within a mental image, the longer it takes the subject to reach it in his mind, thus duplicating a perceptual situation.

Barthes' [12] has provided a theoretical understanding of sketching as a method and process of communication. He states that the signifier and sign can apply linguistically, as per the work of Saussure, and visually, both involving a system and syntagm. The system provides the units or 
language that constitute the syntagm, i.e.; the individual marks and their meaning to the designer. The syntagm is the macro unit of information transmitted; that of the sketch as composed from a collective of marks - Barthes likens this to the spoken sentence. The literal image is a denotation of the abstract form, and the symbolic image is what it means either through idiolect or wider language. 'All images are polysemous; they imply, underlying their signifiers, a 'floating chain,' of signifieds, the reader able to choose some and ignore others, ' [13], (p38-39). Particularly pertinent to sketching is the notion that when the symbol is inadequate, the sign outruns its meaning. Barthes [13] cites Christianity as an example of this where the cross is the signifier and Christianity the sign: a cross conveys far more meaning than its signifier is capable of showing. This can be applied to the complex meanings contained within design sketches which go beyond their mere appearance on paper.

Also relevant to the language of sketching is the plane of content from where conceptual information is stored, i.e.; the abstract world of the designer's mind. The plane of expression relates to the sketching environment and the real world where concepts are made manifest. The relationship between these two planes, according to Barthes [13], creates the designer's own plane of reference and is made from the language of the discipline under consideration, personal experience and the Gestaltising effects of the mind during interpretation. This creates the designer's idiolect - his own personal language used during sketching. Drawings, he suggests, can be coded at three levels. They can be rule-governed, when the reproduction of an image or concept requires the application of a set of rules, i.e.; perspective. They can have divisions between significant and insignificant, where not every piece of information is or can be reproduced within the coding of a drawing. He also considers the value apprenticeship, where all codes demand a level of study and application to be successful in their use, this being particularly relevant to the purpose of this study.

\section{Taxonomies}

Ferguson [14] offers an early taxonomy for sketching, including the, "thinking sketch", referring to Leonardo's sketches and those of contemporary engineers as a tool for visual thinking, the, "prescriptive sketch," used for specification of a final solution and the, "talking sketch," (p.96-97), used to communicate with others during the design process. Although beneficial in understanding of the role of sketching to design, this early taxonomy is perhaps too simplistic for contemporary consideration.

Pei, et al. [15] offer a more developed and hierarchical taxonomy involving sketches, models, drawings and prototypes used during design concept development. Personal, shared, persuasive and handover sketches are further classified. They deconstruct personal sketches into idea sketches, study sketches, referential sketches and memory sketches. The idea sketch is to, "allow the developer to externalise his thoughts quickly," (p.12), and is most relevant to this research, as is the study sketch, used to investigate scale, structure and layout based on idea sketches. Their definition of the referential sketch is of one that records information and observations for future use - conversely, memory sketches recall past thoughts via the use of conceptual tools including mind-mapping. They also identify shared sketches; these convey information to members of the design team, tend to contain annotation and are more visually developed. Coded sketches contain symbolic information relative to specific aspects of the design whereas information sketches are intended to be understood across a wider group. Persuasive sketches are intended to sell a concept, often in the form of a rendered visual, and handover sketches contain information for manufacture.

Eckert et al.'s [16] observations of the Across Design Project by the University of Cambridge and MIT, introduces the term, 'Conscription device,' (p.247), to explain the manipulative effect of sketches as communication tools. As with Pei, et al. they regard the sketch as an intrinsic language, functioning between individuals within the design process and define designer communication using sketches as functioning on four levels: with themselves, with peers, within multidisciplinary design groups and with lay members of the design process, including clients. They cite, Star \& Griesemer [17] to define boundary objects as those that convey information to persons of different expertise. Eckert at al. draw parallels with the sketch - it can convey information to persons of different disciplines for different purposes, even though they do not understand the relevance of that sketch for each other. Star \& Griesemer refer to an "ideal type," (p.410); an artefact that can transmit information in a clear enough manner for purpose while lacking detail, (as per a development sketch), while a, "standardised form," ( $\mathrm{p} .411)$, is a method of communication across multiple groups each with their own set of priorities, as with a more developed sketch.

\section{Processes Embodied by Sketching}

Goldschmidt [18] and has proven one of the most critical contributors to the theory of design sketching for this research. She presents experiments conducted by Massachusetts Institute of Technology, where she presents observations of, "moves," and, "arguments," as two distinct types of reasoning embodied by sketching: the, "move," being a tangible proposition within the process, and the, "argument," (p.35-6), being a conceptual micro-activity on the part of the designer within that process. She classifies sketch activity into three distinct areas: "moves made while actively sketching, moves made while contemplating sketches and reading off them and moves with no graphic input," (p.127). She proposes that sketching can be a representation of either linear or diverse thought, acts as a means to test and develop ideas and ends once the hard-line activity, (e.g. draughting), takes place. She coins the term, Interactive Imagery: the process of imaging, sketching and resketching images until useful information can be extracted 
from them. "Sketching is not merely an act of representation of a preformulated image...it is more often than not, a search for such an image."(p.131). On the purpose of sketch function during the design process, she devises a, "seeing as, " and, "seeing that," (p.131), structure. "Seeing as," utilises a Gestalt approach during sketch thinking, using the mind's eye to develop ideas. "Seeing that," relates to the entity that is being designed and applying a non-figural approach to considering it - using the tangible output of the sketch process as a platform for further thinking.

Goldschmidt [19] further anatomises sketch activities with the creative process, referring to leaps - sudden insights within the mind of the designer "one in which the distance in time or place among relevant moves is too great to track,"(p.200). Serial processes are identified where sketches are produced one after another, but not necessarily relying on sequential thought within a linear process, and sequential sketch activity that is likened to machine processes where a set of information is developed based upon the previous set of information. She also observes the importance of expertise for the effective handling of the sketching process: novices often find themselves unable to detach from an image they have created that they are unhappy with, thus forming a negative development within the process. She suggests this is less the case with more experienced designers who have a broader range of macro-experiences to draw upon.

On the development of digital tools to replace traditional sketching methods, Goldschmidt [19] argues, "persistent attempts to replace sketching with algorithmic, computational techniques, (largely computer-based), have so far failed to contribute to design reasoning in any way...the cause lies not in insufficient development of these new methods but in the inherent potency of the sketching tool," ( p.215). This statement although over twenty five years old, is still relevant to the intrinsic ability of sketching to support the designer's creative and cognitive processes.

Schon [20] considers problem-solving activities across multiple disciplines including that of design for which he emphasises the importance of sketching. He states that designers are involved in a: 'transactional,' relationship with the design and are in a "reflective conversation with the situation," (p.4) for which, "the act of drawing can be rapid and spontaneous, but the residual traces are stable...the graphic world of the sketchpad is the medium of reflection-in-action," [21] (p.153). He suggests that design situations involve material situations and apprehension of those though sensory appreciation, and proposes that the designer constructs an abstract world of objects and relationships through which he addresses the design problem [20]. He says the design world is personal to the designer created according to his perceptions, and believes the more innovative a design episode, the more likely it is to be unique to the designer: 'The designer designs not only with the mind, but with the body and the senses,' [20] (p.7). Similar to Goldschmidt's proposition of Seeing As and Seeing That, he refers to the process of 'Seeing-drawing-seeing,' - 'a designer sees moves and sees again,' (p.7). His notion of seeing embraces the use of faculties other than sight; the terms, "recognise, detect, discover and appreciate," (p.7) are proposed to reinforce the concept of design being a bodily and sensory process.

Schon \& Wiggins [22], elaborate on Goldschmidt's notion of experience as vital to effective problem-solving. They suggest that the more experienced a designer, the more domains he can work in at once; the designer's move to address a single term being effective in many domains at once. A lack of experience and its effects on working memory limitations is also noted, especially where the act of seeing-moving-seeing is required in the management of complexity within a design problem.

The themes of Fish \& Scrivener's [23], eminent paper are still valid today, especially those relating to the cognitive aspects of visual imagery. They discuss the tolerances and indeterminacy of manual sketching that enable perception of more than one option at once, and compare this process to that of the computer where the designer can be forced down the route of developmental detail too early, potentially harming the design process. They suggest that sketches combine both images collected by the eyes with those generated from memory and clarify the difference between sketching from imagination and from observation: observation sketching relies on the repeated refreshing of overt attention to an external image, whereas sketching from memory relies on the generation and manipulation of mental images.

Fish \& Scrivener also consider the difference between descriptive and depictive information and the function of sketches in the relationship between them. The language sketching uses enables the designer to create their own mental images based upon what they see on the page; this may influence the image within the designer's mind and this ambiguity can initiate recognition and further mental imagery. They lament the inability of the computer to offer the same serendipity of manual sketching: "sketches have the important function of assisting the mind to translate descriptive propositional information into depiction. Depictive information may then be scanned by attentional processes to extract new and perhaps original descriptive information, which in turn can lead to new depiction," (p.118).

Goel's [8] widely cited work on the nature of ill-structured problems, such as those addressed by designers, considers the inadequacy of cognitive science and its reliance on structured symbolism to address the complexities of language used during the early stages of the design process. His experiments with graphic designers conclude that freehand sketches convey condensed ambiguous information which offers the designer new possibilities for interpretation - something thing that a digital alternative, at the time of publication, could not replicate. He also develops a coding system for sketches based on his experiments: lateral transformations occurring within a solution space during the creative shift to alternative concepts: "... when a new idea is 
generated, a number of variations of it quickly follow. The variations expand on the problem space... One actual gets the sense that the exploration and transformation of ideas is happening on the paper in front of one's eyes as the subject moves from sketch to sketch," (p.200). Conversely, vertical transformations occur during the sequential development of a concept towards a solution. He also identifies reinterpretation as a vital function of sketches, allowing the observer to apply new meaning to an existing set of information.

Cross [24] reiterates the issue of design fixation and attachment to concepts, which is readily seen in HE design studios, particularly among sketch inhibited individuals. He believes fixation can be both beneficial and detrimental to the quality of design output: avoiding an overload of design information so a design can be established, but with the potential for preventing a design from being properly developed. He refers to Akin \& Akin's [25] research into the design problem-solving process, suggesting that in order to create new concepts through sudden mental insight, the designer's frame of reference needs to be broken. Shifts in mode between drawing, examining and thinking enable design discoveries to be made and gathering information, drawing and reflection in combination with quick switches between these modes are deemed to be conducive to the most successful progress in problem-solving.

\section{Educational Issues}

Schenk's [26] research over thirty years into the position of design sketching and its relevance to education and industry underpins this research and has offered a theoretical foundation and justification for investigating sketch inhibition among undergraduate designers. She suggests that secondary education does not equip students with drawing skills required for HE studies and that consequently, industry's needs are not being met by the drawing abilities of graduating designers. She also observes the standard of drawing among newly graduated and early career designers has been dropping over the past few decades and as a result, impedes the activities of commercial design studios. She considers the teaching of drawing within design education; that it is problematic and sometimes inconsistent with the needs of designers. It is often based on fine art practice and observation as opposed to developing a visual syntax to enhance the mental processes required by the designer.

Schenk [27] also exposes a lack of consistency in thinking about the importance of drawing within institutions, stating that Quality Assurance Agency for Higher Education guidelines on the teaching and learning of drawing in HE institutions are limited to a single sentence. She also alludes to friction between the disciplines of fine art and design drawing which serve very different purposes for the designer, those of observation and of conceptualisation respectively. Historically many drawing tutors came from a fine art background and taught observation-based skills that fulfil only part of the needs of the design student. As such she believes the teaching of design drawing should be contextualised within the language of the specific design discipline being studied.

A precis of the main findings from the literature review is presented below in tabular form, (see table 1). The grey sections indicate where literature from more than one source is identified as divergent or presenting very similar data to the study: this is of particular interest to the study. Presented within the table are the definitions of sketching as language, the issues of cognition and the benefits of sketching to that activity, the individual processes within sketching, and the properties of the sketching tool for information handling during the complex design development process.

\section{The Symptoms of Sketch Inhibition}

Specific reference to sketch inhibition in the literature is sparse, only three papers $[3,2,4]$ addressing the phenomenon explicitly: Booth, et al.[3] identify several types of sketch inhibition during the design process and these fall into three distinct areas:

\section{Issues of the individual, including:}

- Intellectual inhibition, or a lack of awareness of the benefit of sketching to the design process,

- Skill-set inhibition; the lack of expertise needed to use sketching effectively,

- Personal inhibition; ego-driven issues of perfectionism that impair the creative flow, and,

- Situational inhibition, when a designer does not feel in the right state of mind to sketch.

Secondly, social issues, including,

- Social and comparative inhibition or the fear of being judged unfavourably by others during the process of creating sketch material, and,

- Social loafing which involves a lack of input in a group situation, either through fear of judgement or laziness.

The third area Booth et al. identify is that of technological inhibition caused by a prevalence of digital tools available in the designer's environment which then leads to a disinterest in manual sketching. However, digital tools present their own issues. Coyne, et al. [28] acknowledge inexperience with CAD as problematic in enabling students to realise their ideas: "If you only know how to draw a box, your building will be a box, and if you know how to design anything on the computer you can design anything, "'(p.270). 


\begin{tabular}{|c|c|c|c|c|c|}
\hline \multicolumn{6}{|c|}{ The nature of sketching } \\
\hline \multirow[t]{4}{*}{ Language } & Bilda et al.[7] & Barthes [12,13]; & Eckert et al.[16] & Star \& Griesemer [17]: & $\begin{array}{c}\text { Fish \& } \\
\text { Scrivener[23]: }\end{array}$ \\
\hline & Imparts a dialogue & A language & & & \\
\hline & & $\begin{array}{l}\text { Symbolism used within } \\
\text { idiolect or wider language }\end{array}$ & $\begin{array}{l}\text { Conscription } \\
\text { devices }\end{array}$ & Boundary objects & $\begin{array}{c}\text { Depictive } \\
\text { information(as } \\
\text { opposed to } \\
\text { descriptive) } \\
\end{array}$ \\
\hline & & $\begin{array}{l}\text { Can be rule governed, as with } \\
\text { perspective }\end{array}$ & & & \\
\hline \multirow[t]{3}{*}{ Cognition } & Kosslyn [11]: & Bilda \& Gero [9]: & & & \\
\hline & $\begin{array}{c}\text { Externalisation of } \\
\text { mental } \\
\text { imagery-depictive as } \\
\text { opposed to } \\
\text { propositional } \\
\end{array}$ & & & & \\
\hline & $\begin{array}{l}\text { Manages working } \\
\text { memory limitations }\end{array}$ & $\begin{array}{l}\text { Importance of sketching to } \\
\text { offload }\end{array}$ & & & \\
\hline \multirow{8}{*}{$\begin{array}{l}\text { Processes } \\
\text { within } \\
\text { sketching }\end{array}$} & Goldschmidt [18,19]: & Schon $[21]:$ & Goel[8]: & & \\
\hline & Interactive imagery & A reflective conversation & & & \\
\hline & $\begin{array}{l}\text { Move-tangible } \\
\text { proposition }\end{array}$ & & & & \\
\hline & $\begin{array}{c}\text { Argument-conceptual } \\
\text { micro-activity }\end{array}$ & & & & \\
\hline & $\begin{array}{c}\text { Seeing as - ultilisation } \\
\text { of Gestalt to identify } \\
\text { possibilities }\end{array}$ & Seeing-drawing-seeing & & & \\
\hline & $\begin{array}{c}\text { Seeing } \\
\text { that-consideration of } \\
\text { the image }\end{array}$ & & & & \\
\hline & Serial process & & $\begin{array}{c}\text { Vertical } \\
\text { transformations } \\
\end{array}$ & & \\
\hline & Sudden leaps & & $\begin{array}{c}\text { Lateral } \\
\text { transformations }\end{array}$ & & \\
\hline \multirow[t]{2}{*}{$\begin{array}{l}\text { Information } \\
\text { handling }\end{array}$} & $\begin{array}{c}\text { Fish \& Scrivener, Goal } \\
\text { [8]: }\end{array}$ & Goldschmidt[10]: & Fish \& Scrivener & $\begin{array}{c}\text { Goldschmidt[19],Schon } \\
\text { \&Wiggins[22]: }\end{array}$ & Akin \& Akin[25]: \\
\hline & $\begin{array}{l}\text { Enables } \\
\text { re-representation-is } \\
\text { indeterminate }\end{array}$ & $\begin{array}{c}\text { Storage of design development } \\
\text { information }\end{array}$ & $\begin{array}{l}\text { From imagination } \\
\text { or observation }\end{array}$ & Requires expertise & $\begin{array}{l}\text { Requires shifts in } \\
\text { mode between } \\
\text { drawing, } \\
\text { examining } \\
\text { \&thinking }\end{array}$ \\
\hline
\end{tabular}

Table 1. Table showing a comparative precis of the main literature findings relevant to the nature of sketching.

\section{Causal Factors}

These have been identified at this stage via the literature as belonging to the broadly distinct areas of psycho-social, intellectual, skill-set and technological, or a combination of these. Fear of failure, as mentioned above by Booth et al. [3] is also identified by Leblanc [1] who suggests that, "the development process is widely misunderstood or inaccessible," (p.2), and has resulted in a common belief among students that experimentation and failure, a normal part of design, are somehow unacceptable. Because of this fear, students rush into visualisation as soon as they have a suggestion of a concept, omitting stages of evaluation and refinement essential for a fully developed design solution.

Leblanc's [1] research with industrial design students at Montreal University demonstrates the lack of intellectual awareness among students, who "...struggle with the creative process, especially with sketching, exploring and developing ideas into mature designs. Many see sketching only as a means of visualization and rarely know how to use it as a creative thinking tool," (p.1) She also suggests an over-reliance on technology as a causal factor: "students are judged by their skills with these tools rather than their creativity or problem-solving ability...(which)...nurtures the misconception of design as an aesthetic gesture rather than an intellectual, creative thought process that helps solve problems and drive innovation," (p.5). The essential processes of design embodied by its practical activities have been replaced with what she describes as, "more gratifying digital tools, "'(p.2).

The culture of immediacy among millennial learners, [29] appears to be a causal factor of sketch inhibition. Interestingly, the expansion in the number of higher education design courses over recent decades may have, ironically, had a part to play in the increase in numbers of inhibited students. This has come about due to some institutions applying a less rigorous approach to recruitment, Lambert \& Firth [31], observing, "Applicants no longer have 
to compete against each other, and consequently students' drawing skills upon embarking on a design degree are generally much less adept than in the 1980s," (p.5).

\section{Management of Sketch Inhibition}

The management of sketch inhibition is barely touched upon anywhere in the literature. It has however, been addressed by $\mathrm{Hu}$ et al. [2] who consider how warm-up exercises among engineering students affect their cognitive states during concept development. They gave a group of engineering students geometric sketching exercises, art-based sketching exercises or no warm-up exercises prior to a simple design task. Electro Cardio Graph and Galvanic Skin Response tests were used prior to and after the task together with a NASA TLX questionnaire to establish participants' emotional responses. They concluded that art-based warm-up exercises were helpful in the process of concept generation and appeared to benefit younger participants most. Female participants unexpectedly expressed an increase in pride in their sketch output after the exercises. This suggests that management of sketch inhibition is possible and shows further potential for this research.

Leblanc's [1] research suggests the attitude of the individual is vital in overcoming sketch inhibition. She suggests, "those with high ambitions and strong self-motivation manage to overcome the deficit," (p.2) and believes that those with the will to confront their fears and determination to develop and maintain new skills have a good chance of becoming fluent and confident sketchers. However, those without that determination will often develop other skills on order to compensate for their lack of ability. Creating that motivation among inhibited students will be the challenge for educators.

\section{Conclusions \& Recommendations}

At this stage of the research, it is clear that there exists little data regarding the causal and symptomatic factors associated with sketch inhibition, and its management within HE. However, a number of issues have emerged from the research which may be of relevance:

- The importance of student awareness of the functions of sketching and its benefit to design. At present there is little consideration given to understanding its purpose and processes. Rather than deferring their creativity from analogue to digital process with no understanding of the differences between the two, greater understanding of the role of sketching could enable student designers to make more appropriate choices about their processes.

- The need for greater student confidence to connect with the indeterminacies of the design process without fear of 'failure' in front of peers. The lateral, re-interpretive functions that sketching provides could persuade the inhibited individual to engage with the design process with less anxiety (rather than to cling onto a simplistic, linear approach), and warrants further investigation. This would however, rely on a better understanding of the processes as mentioned above.

- Greater structure in the pedagogy of teaching sketching could be of potential benefit rather than assuming it is a purely intuitive process. However, student resistance may be an issue, based on Skiba's [30] observations. Teaching a toolkit that the student can refine according to their own needs, rather than leaving learning to chance, may well be appropriate.

Further qualitative research into these issues is of course necessary, with the need for extensive primary data in order to build a more accurate picture of the phenomenon. A semi-structured/guided conversation method for data gathering is yet to be applied to educators and influencers within education to establish in more depth the human issues and relationship between higher education and its relationship with ideation sketching.

A series of semi structured interviews with design undergraduates from multiple design disciplines, (according to Gross \& Do [5]) will be undertaken and endeavour to, through a double coding process, (framed and emergent), establish common causal and symptomatic factors together with reflections of individual participant's relationship with sketching during design. It is intended that, by this stage, the data will enable a move towards a developmental pedagogical framework for the management of sketch inhibition among undergraduate designers.

\section{Funding}

This paper was produced during $\mathrm{PhD}$ study funded by a fees-only bursary from De Montfort University.

\section{REFERENCE}

[1] Leblanc T. Sketching as a Thinking Process. In: DS82: Proceedings of the 17th International Conference on Engineering and Product Design Education (E\&PDE15), Great Expectations: Design Teaching, Research \& Enterprise. 2015.

[2] Hu W-L, Booth J, Reid T. Reducing Sketch Inhibition During Concept Generation: Psychophysiological Evidence of the Effect of Interventions. In: ASME 2015 International Design Engineering Technical Conferences and Computers and Information in Engineering Conference. American Society of Mechanical Engineers; 2015.

[3] Booth JW, Taborda EA, Ramani K, Reid T. Interventions for teaching sketching skills and reducing inhibition for novice engineering designers. Design Studies [Internet]. Elsevier; 2016;43:1-23. Available from: http://linkinghub.elsevier.com/retrieve/pii/S0142694X15000 
952

[4] Farzaneh H., Hashemi Kaiser M K., Lindemann U. Creative processes in groups - relating communication, cognitive processes, and solution ideas, Proceedings of the 2nd International Conference on Design Creativity. 2012. Glasgow, UK.

[5] Gross MD, Do EYL. The design studio approach: learning design in architecture education. Design Education Workshop/NSF, College of Computing, George Institute of Technology [Internet]. 1997;8-9. Available from: http://depts.washington.edu/dmgftp/publications/pdfs/edutec h97-eyd.pdf

[6] Kara H. Analysing Data for your PhD: an introduction. Knowmore Publishing; 2016.

[7] Bilda Z, Gero JS, Purcell T. To sketch or not to sketch? That is the question. Design Studies. 2006; 27(5).

[8] Goel V. Sketches of Thought: A Study of the Role of Sketching in Design Problem-Solving and its Implications for the Computational Theory of Mind. PhD dissertation; University of California, Berkeley; 1995.

[9] Bilda Z, Gero JS. Does sketching off-load visuo-spatial working memory? Studying Designers [Internet]. 2005;5, 2005, 145-159. Available from: http://books.google.com/books?hl=en\&lr=\&id=okrxYWkX6 nYC\&oi=fnd\&pg=RA1-PA145\&dq=Does + sketching + off-lo ad+visuo-spatial+working + memory $\% 253$ F\&ots=wIMtxCB9 ep\&sig=PvugigvRnRVtUa5Gk6mJNXw08yk

[10] Goldschmidt G. The Backtalk of Self-Generated Sketches. Design Issues [Internet]. MIT Press; 2003; Vol 19(No 1). Available from: http://files.onearmedman.com/fordham/goldschmidt2003.pdf

[11] Kosslyn SM. Image and brain: The resolution of the imagery debate. MIT press; 1996.

[12] Barthes R. Elements of semiology. London: Jonathan Cape; 1967.

[13] Barthes R. Image, Music, Text. St Ives, UK: Clays Ltd; 1977.

[14] Ferguson E. Engineering and the Mind's Eye. Cambridge, MA: MIT Press; 1992.

[15] Pei E, Campbell I, Evans M. A taxonomic classification of visual design representations used by industrial designers and engineering designers. Design Journal. Taylor \& Francis; 2011;14(1), 64-91.

[16] Eckert C, Blackwell AF, Stacey M, Earl C, Church L. Sketching across design domains: Roles and formalities. Artificial Intelligence in Engineering Design Analysis \& Manufacturing [Internet]. Cambridge University Press; 2012; 26 (3), 245-266. Available from: http://journas.cambridge.org/abstract_S0890060412000133
[17] Star S, Griesemer J. Institutional ecology, translations and boundary objects: Amateurs and professionals in Berkeley's Museum of Vertebrate Zoology, 1907-39. Social Studies of Science. Sage Publications; 1989;19(3):387-420.

[18] Goldschmidt G. Sketching in design: past, present, future, Proceedings of the Environmental Design Research Association, North Carolina State University School of Design, 1989.132-138.

[19] Goldschmidt G. Serial Sketching: Visual Problem-Solving in Designing. Cybernetics and Systems [Internet]. 1992; 23 (No2): 191-219. Available from: https://www.researchgate.net/publication/245326359_Serial _Sketching_Visual_Problem_Solving_in_Designing

[20] Schon D. Designing as a reflective conversation with the materials of a design situation. In: Edinburgh Conference on Artificial Intelligence in Design. Edinburgh; 1991.1-50.

[21] Schon D. The Reflective Practitioner: How Professionals Think in Action. New York: Basic Books; 1983.

[22] Schon D, Wiggins G. Kinds of Seeing and their Functions in Designing. Design Studies. Elsevier; 1992;13(2):135.

[23] Fish J, Scrivener S. Amplifying the mind's eye: sketching and visual cognition. Leonardo. JSTOR; 1990;23(1):117-26.

[24] Cross N. Natural intelligence in design. Design Studies. Elsevier; 1999;20(1):25-39.

[25] Akin Ö, Akin C. Frames of reference in architectural design: analysing the hyperacclamation (Aha-!). Design Studies. Elsevier; 1996;17(4):341-61.

[26] Schenk P. Reflections on the teaching of drawing in the digital age: attitudes of senior academics in the United Kingdom to the place of drawing tuition on the design curriculum in higher education. Art, Design Communication in Higher Education. 2005;4(3):189-203.

[27] Schenk P. The Why and How of Drawing: A 20 Year Shift in Design Procedures and Priorities. In: European Academy of Design Conference. Bremen, Germany: European Academy of Design; 2005.1-11.

[28] Coyne R, Park H, Wiszniewski D. Design devices: digital drawing and the pursuit of difference. Philosophy of Design [Internet]. 2002; 23(3): 263-86. Available from: http://www.sciencedirect.com.proxy.library.dmu.ac.uk/scien ce/article/pii/S0142694X01000382

[29] Skiba DJ. The Millennials: have they arrived at your school of nursing? Nursing Education Perspectives. 2005; 26(1):370-1.

[30] Lambert I, Firth R. Pencils Don't Crash. In: DS 38: Proceedings of E\&DPE 2006, the 8th

[31] International Conference on Engineering and Product Design Education, Salzburg, Austria, 07-0809 2006. 